\title{
PERCEPÇÕES ACERCA DA LICENCCA-MATERNIDADE NOS PROGRAMAS DE PÓS-GRADUAÇÃO: O DIREITO DAS ESTUDANTES E O CONTEXTO ATUAL DE AVALIAÇÃO DOS CURSOS
}

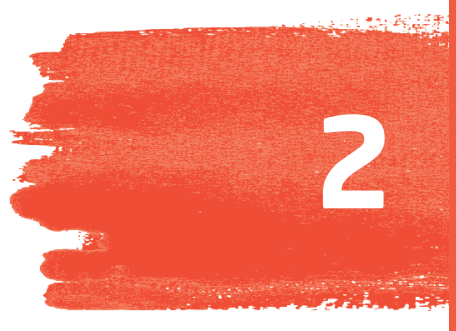

\section{FABÍOLA DE SAMPAIO RODRIGUES GRAZINOLI GARRIDO LORRANNE CARVALHO DA COSTA ${ }^{4}$ MONIQUE BEATRIZ DA SILVA LASSAROT ${ }^{5}$}

m 2016, 15.525 estudantes concluíram o doutorado (8.212 mulheres e 7.313 homens). Segundo aponta o mesmo censo do $\mathrm{CNPq}$, presente no Painel Lattes, outros 32.664 defenderam o mestrado nesse mesmo ano, sendo 18.248 mulheres e 14.416 homens. No período entre 2007 e 2016 o número absoluto de mulheres superou o de homens na conclusão dos cursos de pós-graduação. Nesse sentido, a proximidade entre os números assinala a necessidade crescente e antiga de se discutir questões atinentes particularmente às mulheres. Principalmente pela faixa etária que compreende em sua maioria mulheres em idade fértil.

As consideráveis mudanças pelas quais vem passando a sociedade pós-moderna resultaram em grandes alterações na vida da mulher, principalmente no que concerne a sua demanda por

3 Professora Doutora Associada - DCMA/UFRRJ, PPGPDS. Email: fabiola_srg@yahoo.com.br

4 Acadêmica do curso de Direito da Universidade Federal Rural do Rio de Janeiro - Instituto Três Rios/UFRRJ - ITR. Email: lorranne_carvalho@hotmail.com

5 Acadêmica do curso de Direito da Universidade Federal Rural do Rio de Janeiro - Instituto Três Rios/UFRRJ - ITR. Email: monilassa@gmail.com 
igualdade profissional, salarial e educacional. Segundo Pinheiro e Garrido (2016), a participação feminina no mercado de trabalho se concentra no setor de comércio, o que trouxe consigo a renda de 1,01 a 1,50 salários mínimos ao mês. Inversamente, cada vez mais aumenta o número de mulheres que ingressam nas universidades em busca dos programas de pós-graduação como forma de dar prosseguimento à pesquisa e aos estudos.

Mais do que nunca, a mulher assume espaços nos ambientes acadêmicos e busca perpetuar essa presença. Todavia, para além das necessidades acadêmicas, as demandas do lar e da vida materna insurgem concomitantemente, gerando a necessidade de criação de meios pelos quais tais obrigações não colidam - o que ocorre quando as pesquisadoras, no decorrer dos vínculos de bolsistas, engravidam. É Nesse cenário de assistência pós-parto atribuída às estudantes nos programas de pós-graduação que o presente estudo se debruça.

Há um senso comum que atribui ao período de licença-maternidade um gozo de férias, descanso, deleite. Os conhecedores de uma biologia rasa, no entanto, facilmente poderiam alterar a denominação desta garantia legal para licença natalícia. No intuito de se garantir a vida do nascituro com saúde plena e integração familiar, sabe-se que a mãe não dispõe de um período de férias.

Importa destacar que, para além da transformação da mulher em mãe, há o contexto legal que deve ser observado. As obrigações em relação à cidadania da criança estão previstas em leis federais, portarias do Ministério da Saúde (MS), do Ministério do Trabalho e Emprego (MTE) e no Estatuto da Criança e do Adolescente (ECA), das quais pouco se discorre quando diante dos aspectos da licença-maternidade, como disposto no quadro 1. 
Quadro 1 - Dispositivos legais discorrem sobre a obrigatoriedade em relação ao cumprimento do Plano Nacional de Imunização e regulamenta a concessão de benefícios do governo e a admissão das trabalhadoras e trabalhadores com base na apresentação do atestado de vacinação.

\begin{tabular}{|ll|}
\hline Dispositivo Legal \\
\hline Decreto n. 78.231, de 12 de agosto de 1976. & $\begin{array}{l}\text { Programa Nacional de Imunizaç̃es, } \\
\text { estabelece normas relativas à } \\
\text { notificação compulsória de doenças }\end{array}$ \\
\hline Art. 14 da lei n. 8.069, de 13 de julho de 1990. & $\begin{array}{l}\text { Dispõe sobre o Estatuto da Criança e do } \\
\text { Adolescente e dá outras providências }\end{array}$ \\
\hline $\begin{array}{l}\text { Art. } 5 \text { da portaria do MS n. 597/GM, em } 8 \text { de abril de } \\
2004 .\end{array}$ & $\begin{array}{l}\text { Obrigatoriedade de apresentação do } \\
\text { atestado de vacinação }\end{array}$ \\
\hline Art. 84 do decreto n. 3.048, de 6 de maio de 1999. & $\begin{array}{l}\text { Aprova o Regulamento da Previdência } \\
\text { Social, e dá outras providências }\end{array}$ \\
\hline
\end{tabular}

Fonte: elaboração dos autores.

Um breve percurso histórico pela luta das mulheres contra discriminações e a favor da isonomia no tratamento pode apontar avanços significativos na garantia dos direitos atuais. Por outro lado, além do exercício domiciliar na graduação, o direito à licença-maternidade era concedido apenas a mulheres que estivessem no mercado de trabalho. Às estudantes matriculadas na pós-graduação bastava seguir a sugestão de seus orientadores e orientadoras no sentido de proceder ao trancamento e, eventualmente, abandono do curso.

Até o ano de 2006, as pesquisadoras de pós-graduação não possuíam nenhuma garantia de prosseguimento da bolsa, bem como dos seus projetos caso engravidassem no decorrer da pesquisa, motivo pelo qual, muitas abandonavam os cursos para se dedicar integralmente à família. A partir da portaria n. 220 da Capes, o panorama passou a ser regulado, atribuindo o direito à licença-maternidade, também, às mulheres nos programas de pós-graduação.

Ao compreender a licença-maternidade enquanto um direito constitucionalmente garantido às mulheres empregadas de não 
prestarem serviços no período de vigência da licença, porém, recebendo remuneração e computando o estágio como tempo de serviço, tal aplicação quando vislumbrada às estudantes de pós-graduação revela uma interpretação extensiva do referido direito previsto no art. $6^{\circ}$ da Constituição Federal (Schifino, 2015).

Destarte, a presente pesquisa tem como objetivo verificar a aplicação do instituto da licença-maternidade na pós-graduação, a efetividade dessa garantia, bem como sua abrangência e seu conhecimento perante as pesquisadoras. Para tanto, utilizou-se de entrevistas com pesquisadoras de cinco universidades brasileiras, aplicando-se o método de abordagem dedutivo, partindo-se, primeiramente, dos estudos sobre a legislação pertinente, posteriormente analisando-se a sua aplicabilidade.

\section{DOS DIREITOS DA MULHER FRENTE O MERCADO DE TRABALHO}

Inicialmente, cumpre analisar o contexto histórico acerca do espaço feminino no mercado de trabalho, bem como seus reflexos na vida das mulheres para que se possa vislumbrar a importância da garantia ao direito à licença-maternidade ao longo dos anos.

Nesse contexto, a incidência da mulher no mercado de trabalho remonta à II Guerra Mundial em dados mais expressivos, embora já existissem reflexos isolados na história:

Uma das mudanças mais notáveis na oferta de trabalho no pós-guerra tem sido o grande aumento da participação feminina na procura por emprego e ocupação. Embora o fenômeno já fosse incipiente antes da Segunda Guerra Mundial, logo após as mulheres entraram pesadamente no mercado de trabalho (Soares, 2002). 
No Brasil, a inserção da mulher no mercado de trabalho teve grande expressividade a partir da década de 90 , representando os reflexos do avanço e crescimento da industrialização no país, no contínuo processo de urbanização e na consequente redução das taxas de fecundidade nas famílias. Assim:

Para as mulheres a década de 90 foi marcada pelo fortalecimento de sua participação no mercado de trabalho e o aumento da responsabilidade no comando das famílias. A mulher, que representa a maior parcela da população, viu aumentar seu poder aquisitivo, o nível de escolaridade [...] (Probst, 2003).

Ocorre que, para além dessa inserção crescente, a mulher enquanto sujeito de direitos e detentora de garantias, em igualdade e paridade, como previsto no art. $5^{\circ}$, I, da Constituição Federal, deve ser compreendida dentro das suas particularidades inerentes a sua existência, tal como a maternidade, visto que embora "[...] trabalhar fora de casa é uma conquista relativamente recente das mulheres. Ganhar seu próprio dinheiro, ser independente e ainda ter sua competência reconhecida é motivo de orgulho para todas" (Probst, 2003). Probst (2003) propõe ainda que não se pode desconsiderar o fato de que atualmente "[...] o perfil das mulheres é muito diferente daquele do começo do século. Além de trabalhar e ocupar cargos de responsabilidade assim como os homens, ela aglutina as tarefas tradicionais: ser mãe, esposa e dona de casa."

Logo, o entendimento dado à igualdade material, segundo o qual "dar tratamento isonômico às partes significa tratar igualmente os iguais e desigualmente os desiguais, na exata medida de suas desigualdades" (Nery Junior, 1999), traduz, pontualmente, as demandas em que a mulher se debruça para se perpetuar no mercado 
de trabalho - e é nessa toada que a garantia à licença-maternidade se fundamenta. Na necessidade de compreender que a assistência ao papel da mulher enquanto indivíduo social deve se ater, também, ao seu papel enquanto mãe.

\section{DA LICENÇA-MATERNIDADE: CONCEPÇÃO}

$\mathrm{O}$ direito à licença-maternidade representa uma evolução no que diz respeito ao pensamento protecionista do trabalho feminino. Nele está subentendido o esforço dos legisladores em proteger a mulher na sua dignidade (CRFB, art. $1^{\circ}$, III), contra a discriminação (CRFB, art. $3^{\circ}$, IV e $5^{\circ}$, caput, I), bem como no seu livre exercício profissional (CRFB, art. $5^{\circ}$, XIII), tendo em vista a preservação do emprego e salário na interrupção de sua prestação laboral durante a gestação (Assunção, 2007).

Como um direito social, previsto na Constituição, Assunção (2007) entende que a licença-maternidade é inviolável, não podendo assim, ser renunciada. Nesse sentido, o art. 391, parágrafo único da Consolidação das Leis do Trabalho (CLT) veda restrições ao direito da mulher ao seu emprego, por motivo de casamento ou de gravidez, em regulamentos de qualquer natureza, contratos coletivos ou individuais de trabalho.

Nesse contexto, a licença-maternidade, por ser o período em que a mulher, após o parto, fica temporariamente afastada do seu trabalho, confere à mulher a garantia de uma gravidez tranquila $\mathrm{e}$ uma recuperação física e psicológica, necessárias ao pós-parto.

Ademais, proteger a gravidez e a maternidade é preocupação de caráter social com vistas a uma população mais saudável e preservação da dignidade das mulheres, uma vez que através do benefício da licença-maternidade podem cuidar de seus filhos e garantirem $o$ 
direito ao sustento de suas famílias. Muitas mulheres são provedoras do sustento de seus filhos.

Assim, no que concerne à proteção materna, há uma grande preocupação quanto ao aspecto biológico da mulher, devido aos diversos efeitos da gestação - como a recuperação do parto e as alterações hormonais. De fato, a mulher ao longo desse período passa a ser denominada lactante. Ela passa a ser a garantia de nutrição para o nascituro. Um protocolo de vacinação para a criança deve ser observado. Em resumo, uma série de providências que garantem imunidade, proteção, desenvolvimento físico e psicológico à criança estão diretamente vinculados à presença integral da mãe. Mesmo nos casos em que a criança nasce sem vida, a mãe biológica ainda terá o direito à licença-maternidade, tendo em vista a finalidade de proteção da criança e do nascituro.

O art. 227 da Constituição Federal afirma que é dever da família, da sociedade e do Estado assegurar à criança, ao adolescente e ao jovem, com absoluta prioridade a garantia de todos os direitos necessários para seu bom desenvolvimento. Tal afirmação, corrobora a concepção de licença-maternidade, que é a de proteção à mulher e ao nascituro.

De igual modo, "o filho adotivo também tem direito à proteção decorrente da licença-maternidade como forma de propiciar a sua integração e adaptação à entidade familiar que o recebe, medida essencial para o sucesso da convivência com as pessoas deste núcleo" (Dias, 2011).

Nesse sentido, a licença-maternidade à mãe adotante foi estendida. Recentemente, a lei n. 12.873100, de 24 de outubro de 2013, alterou a redação da CLT, estendendo a garantia à licença-maternidade aos empregados adotantes, com o acréscimo do $\$ 5^{\circ}$ ao art. 392-A, e com a inclusão dos art. 392-B e art. 392-C ao texto legal. 
Desse modo, a concepção de licença-maternidade hoje, no Brasil, foi ampliada, tendo em vista que se busca, acima de tudo, a proteção do nascituro e da criança.

\section{DA LICENÇA-MATERNIDADE NO BRASIL: REGULAMENTAÇÃO LEGAL}

A proteção à maternidade nem sempre foi constante em nosso ordenamento jurídico, passando por diversas transformações até atingir os dias atuais. No Brasil, a primeira manifestação acerca da proteção à maternidade se deu pelo decreto federal n. 16.300, de 21 de dezembro de 1923, que previa o descanso de 30 dias para a mulher antes e após o parto.

Nesse sentido, a Constituição de 1934 foi a primeira a assegurar direitos à gestante, como a assistência médica e sanitária. Contudo, com o golpe do Estado Novo, a Constituição de 1937, outorgada por Getúlio Vargas, garantiu à gestante os mesmos direitos já consagrados na Constituição anterior, todavia, foi retirado de seu texto o direito à garantia de emprego durante a gestação (Neiverth, 2009).

Tendo em vista a necessidade de unificação da legislação trabalhista, em 1943 foi promulgada a CLT, contendo normas de proteção ao trabalho da mulher, garantindo assim, estabilidade e licença-maternidade.

As normas de proteção à maternidade surgem obviamente, assegurando situações que advém da natural diferença existente entre homens e mulheres. Ou seja, a mulher gesta e dá à luz uma criança. Essa diferença antes de tudo é biológica. E proteger a mulher enquanto gestante e, depois, durante a amamentação é garantir o futuro da espécie, fim último da existência de qualquer ser vivo. Porém, no momento do ad- 
vento da CLT, suas normas de proteção à maternidade se impuseram como um ônus ao empregador. Não que as exigências fossem descabidas. Até pelo contrário, garantia-se o mínimo para as mulheres que eram ou viriam a ser mães. O problema é que os homens trabalhadores eram tão desprovidos de direitos sociais, que os garantidos às mulheres soavam quase como uma proibição a sua contratação (Cali, 2000).

O art. 392 da CLT dispõe sobre o direito à licença-maternidade de 120 dias, garantindo à mulher grávida o emprego e o respectivo salário. Vejamos:

Art. 392. A empregada gestante tem direito à licença-maternidade de 120 (cento e vinte) dias, sem prejuízo do emprego e do salário.

$\$ 1^{\circ} \mathrm{A}$ empregada deve, mediante atestado médico, notificar o seu empregador da data do início do afastamento do emprego, que poderá ocorrer entre o $28^{\circ}$ (vigésimo oitavo) dia antes do parto e ocorrência deste.

$\$ 2^{\circ}$ Os períodos de repouso, antes e depois do parto, poderão ser aumentados de 2 (duas) semanas cada um, mediante atestado médico.

$\$ 3^{\circ}$ Em caso de parto antecipado, a mulher terá direito aos 120 (cento e vinte) dias previstos neste artigo.

$\$ 4^{\circ}$ É garantido à empregada, durante a gravidez, sem prejuízo do salário e demais direitos:

I - Transferência de função, quando as condições de saúde o exigirem, assegurada a retomada da função anteriormente exercida, logo após o retorno ao trabalho;

II - Dispensa do horário de trabalho pelo tempo necessário 
$\mathrm{Na}$ Constituição Federal de 1988, o direito à licença-maternidade está elencado expressamente enquanto direito social à proteção, à maternidade e à infância, através do caput do art. $6^{\circ}$. Desse modo, o direito à licença-maternidade é expressamente garantido na Constituição Federal:

Art. $6^{\circ}$ São direitos sociais a educação, a saúde, a alimentação, o trabalho, a moradia, o transporte, o lazer, a segurança, a previdência social, a proteção à maternidade e à infância, a assistência aos desamparados, na forma desta Constituição.

Além disso, sua duração é estabelecida pelo art. $7^{\circ}$, inciso XVIII, da CRFB/88, qual seja, de 120 dias, sendo, assim, um direito de afastamento da mulher de seu emprego, para que consiga cuidar de seu filho nos primeiros meses de vida:

Art. $7^{\circ}$ São direitos dos trabalhadores urbanos e rurais, além de outros que visem à melhoria de sua condição social:

VIII - licença à gestante, sem prejuízo do emprego e do salário, com a duração de cento e vinte dias;

Para além da proteção à maternidade, a partir do art. 10, inciso II, alínea b da ADCT, estendeu-se a garantia, ainda, à proteção do emprego da mulher, em que ficou vedada a dispensa arbitrária, ou sem justa causa, da empregada gestante desde a confirmação da gravidez até cinco meses após o parto. O que refletiu na assistência à gestante não apenas no que concerne às demandas inerentes à maternidade, como também no seu direito de permanecer empregada.

Nesse contexto, a maternidade representa um direito intrínseco de todas as mulheres, não cabendo distinguir àquelas que trabalham das que estudam, das que estão em serviço público, ou pri- 
vado, das rurais ou urbanas. É o que vêm entendendo os tribunais superiores, como no caso do agravo seguinte:

\begin{abstract}
ADMINISTRATIVO E PROCESSUAL CIVIL. SERVIÇO PÚBLICO. CONTRATO TEMPORÁRIO. LICENÇA-MATERNIDADE. PROTEÇÃO À MATERNIDADE. I - O direito à licença-maternidade, conferido às trabalhadoras urbanas e rurais, pelo texto constitucional (art. 6, caput c/c art. $7^{\circ}$, XIII da CRFB/88), abrange as servidoras públicas, ainda que temporárias e não-efetivas, de modo que as servidoras contratadas temporariamente pela União devem ter os mesmos direitos concedidos às servidoras públicas federais, não havendo na lei n. 8.745/93, que regula o trabalho temporário, nenhuma regra excluindo tal garantia. II - As servidoras públicas e empregadas gestantes, independentemente do regime jurídico de trabalho a que estão submetidas, têm direito à licença-maternidade e ao respectivo salário maternidade. III - Remessa necessária desprovida. ${ }^{6}$
\end{abstract}

Nesse mesmo sentido, dispõe:

AGRAVO INTERNO - SERVIDORA PÚBLICA GESTANTE - CONTRATO TEMPORÁRIO - ESTABILIDADE PROVISÓRIA (ADCT/88, ART. 10, II, b) - PROTEÇÃO À MATERNIDADE E AO NASCITURO.

O eg. Supremo Tribunal Federal firmou o entendimento de que as gestantes, independentemente do regime jurídico ao qual estejam submetidas, sejam empregadas, servidoras públicas, até mesmo ocupantes de cargo em comissão ou contratadas temporariamente, fazem jus à licença-gestante e,

6 Documento eletrônico. Disponível em: <https://www.jusbrasil.com.br/jurisprudencia/busca?$\mathrm{q}=$ Prote\%C3\%A7\%C3\%A30+\%C3\%A0+Maternidade>. Acesso em: 25 jun. 2017. 
portanto, à estabilidade provisória, como se depreende dos artigos $7^{\circ}$, inciso VIII, 39, parágrafo $2^{\circ}$ e 10 , inciso II, alínea b, do Ato das Disposições Constitucionais Transitórias, todos da Constituição Federal.

A Constituição Federal não excepcionou qualquer situação, tutelando um bem jurídico de especial valor - um interesse público primário.

O interesse da Administração não se sobrepõe ao da sociedade quanto à proteção à gestante, por se tratar de garantia constitucional de proteção à maternidade, prevista no artigo $6^{\circ}$ da Constituição Federal. Recurso não provido. ${ }^{7}$

Essa é a linha de entendimento sobre a qual se debruça a portaria n. 248 da Capes, objeto do presente estudo que visa estender a garantia da licença-maternidade para as mulheres participantes dos programas de pós-graduação.

\section{PORTARIA 220 E 248 DA CAPES: DIREITO À LICENÇA- MATERNIDADE NOS PROGRAMAS DE PÓS-GRADUAÇÃO}

Nessa perspectiva, a licença-maternidade é garantida pela Constituição Federal de 1988, todavia, até alguns anos atrás não atendia mulheres que estavam cursando os programas de pós-graduação. Muitas mães que davam à luz no meio do programa tinham a bolsa interrompida até que pudessem voltar à pesquisa e também perdiam o prazo de até 24 meses para conclusão do mestrado ou 36 meses para doutorado.

No ano de 2006, durante o $1^{\circ}$ Encontro Pensando Gênero e Ciência, a Secretaria de Políticas para as Mulheres reivindicou que a licen-

7 Documento eletrônico. Disponível em: <https://www.jusbrasil.com.br/jurisprudencia/busca?$\mathrm{q}=$ Prote\%C3\%A7\%C3\%A30+\%C3\%A0+Maternidade>. Acesso em: 25 jun. 2017. 
ça-maternidade fosse estendida para bolsistas de cursos de mestrado e doutorado, concedendo, assim, licença de 90 dias.

A Coordenação de Aperfeiçoamento de Pessoal de Nível Superior (Capes) publicou em 2010 a portaria n. 220, a qual determinava que mulheres com bolsas da Capes/MEC e CNPq/MCT poderiam ter seus benefícios estendidos por quatro meses se o parto fosse confirmado durante o programa de pós-graduação:

Art. $1^{\circ}$ Os regulamentos dos programas de concessão de bolsas da Capes, em todas as suas modalidades, passam a atender o seguinte disposto quanto à duração da bolsa: I - No caso de parto ocorrido durante o período da bolsa, formalmente comunicado pelo coordenador à Capes, a vigência da bolsa será prorrogada por até 4 (quatro) meses, garantidas as mensalidades à parturiente.

Contudo, em 2011 foi publicada a nova portaria da Capes n. 248 que revogou a portaria n. 220, com o seguinte texto. Vejamos:

Art. $1^{\circ}$ Os prazos regulamentares máximos de vigência das bolsas de estudo no país e no exterior, iguais ou superiores a 24 (vinte e quatro meses), destinadas à titulação de mestres e doutores, poderão ser prorrogados por até 4 (quatro) meses, se comprovado o afastamento temporário das atividades da bolsista, provocado pela ocorrência de parto durante o período de vigência da respectiva bolsa.

$\$ 1^{\circ} \mathrm{o}$ afastamento temporário de que trata este artigo deverá ser formalmente comunicado à Capes, acompanhado da confirmação pela Pró-Reitoria, coordenação do curso ou orientador, conforme o caso, especificando as datas de início e término do efetivo, além de documentos comprobatórios da gestação e nascimento. 
$\$ 2^{\circ}$ observado o limite de 4 (quatro) meses, não serão suspensos os pagamentos dos benefícios da bolsa durante o afastamento temporário de que trata este artigo.

$\$ 3^{\circ}$ a prorrogação da vigência da bolsa corresponderá ao período de afastamento das atividades acadêmicas, respeitado o limite estipulado no caput deste artigo.

Art. $2^{\circ}$ Revogam-se a Portaria Capes n. 220, de 12 de novembro de 2010 e demais disposições em contrário (Grifo nosso).

Deste modo, hoje está em vigor a portaria n. 248, garantindo assim, que as pesquisadoras, se comprovado o afastamento em virtude do parto, tenham a sua bolsa prorrogada por mais 4 meses. Assim, essas portarias, permitiram que as pesquisadoras pudessem concluir seus trabalhos e ao mesmo tempo conseguissem exercer a maternidade em sua plenitude.

\section{APLICABILIDADE DA PORTARIA N. 248: DADOS EMPÍRICOS}

Assim, para melhor compreensão da aplicabilidade da portaria n. 248 nos casos concretos, insta analisar sua efetividade mediante dados empíricos. Para tanto, buscou-se entender essa implicação mediante questionários online apresentados a pesquisadoras dos programas de mestrado profissional, mestrado e doutorado de universidades brasileiras.

Nessa conjuntura, foram aplicados vinte e quatro questionários a mulheres de diferentes universidades, a fim de se ter um panorama geral dos programas de pós-graduação, sendo que 70,83\% das pesquisadoras entrevistadas cursavam Mestrado, 20,83\% cursavam Mestrado Profissional e 8,3\% cursavam Doutorado. 
As 24 entrevistadas são pesquisadoras das seguintes universidades: Universidade Federal Fluminense (UFF), Universidade Federal Rural do Rio de Janeiro (UFRRJ), Universidade Estadual Paulista (UNESP), Pontifícia Universidade Católica (PUC-RIO), Universidade Estadual de Maringá (UEM), Mackenzie, Universidade Católica de Petrópolis (UCP) e Universidade Federal do Estado do Rio de Janeiro (UFRJ).

Dentre as pesquisadoras, 66,6\% não são bolsistas e 33,3\% são bolsistas, sendo que $78,26 \%$ das entrevistadas não souberam informar se existe licença-maternidade para as mulheres que cursam Mestrado, Mestrado profissional ou Doutorado nos programa nos quais estão inseridas. Ademais, nenhuma das entrevistadas conhecia as portarias n. 220 e n. 248 da Capes.

Nessa perspectiva, quando perguntado às entrevistadas se conheciam alguma aluna dos programas de pós-graduação que não recebeu a bolsa após a gravidez e não deu prosseguimento aos estudos, todas as respostas foram negativas, corroborando com o fato de não terem conhecimento da aplicação da proteção no caso concreto.

Sobre o uso da licença-maternidade pelas próprias entrevistadas durante o seu programa de pós-graduação, todas responderam que não fizeram uso, enquanto 18 afirmaram não conhecer nenhuma pesquisadora que já tenha requisitado a licença durante a pósgraduação e apenas 5 responderam que conheciam mulheres que já tinham requerido.

No que concerne o conhecimento das entrevistadas sobre a licença-maternidade em respostas livres, 10 das pesquisadoras conheciam o termo genericamente como sendo a licença remunerada atribuída à mulher no pós-parto, 7 das entrevistadas conheciam a existência da licença-maternidade apenas nos casos de carteira assinada e de vínculo empregatício, 2 das entrevistadas reiteraram que 
desconheciam a existência da licença-maternidade na pós-graduação, 2 das entrevistadas afirmaram que sabiam da existência, todavia sem mais detalhes, e apenas 1 aduziu que conhecia o direito e demonstrou entendimento sobre $\mathrm{o}$ assunto.

Desse modo, percebe-se que, embora as portarias em comento estabeleçam a defesa dos direitos da mulher gestante nos programas de pós-graduação, na vida prática a realidade destoa da legalidade. Isso porque pouco se conhece e se comenta a respeito da referida garantia para essas mulheres, o que gera o questionamento acerca da efetividade desta previsão.

Ademais, percebe-se que, além de se tratar de portaria relativamente recente, datada de 2011, cuja garantia já devia ser prevista, tendo em vista a longevidade da proteção à licença-maternidade, pouco ou nada se discute a respeito deste tema na doutrina, o que leva ao seu desuso e, indiretamente, ao desamparo a essas gestantes.

\section{AVALIAÇÃO DOS CURSOS DE PÓS-GRADUAÇÃO PELA CAPES: UMA ANÁLISE CRÍTICA}

A despeito da legislação que trata da licença-maternidade, a Capes avalia os cursos de pós-graduação dentro de um quadriênio, resultado da informação anual da produção oferecida pelos programas através da Plataforma Sucupira. Entre os parâmetros avaliados, estão a produção bibliográfica dos docentes, a participação como docente na graduação e na pós-graduação, a produção técnica e a média do tempo de defesa dos estudantes.

Sendo assim, o tempo que o estudante demanda para elaboração e defesa de seu trabalho influencia diretamente na nota do programa. Não há distinção no tempo dos períodos de afastamento por 
doença, licença-maternidade, de outros afastamentos não previstos. $\mathrm{Na}$ avaliação da Capes acontece apenas a averiguação do interstício de forma absoluta. Isso aponta para uma análise que mantém os parâmetros iniciais para avaliação dos cursos.

O estudante que goze da licença-maternidade, seja por nascimento, ou adoção, ou morte da mãe, compõe uma estatística oculta de pessoas que se tornam um entrave para o curso, ou para seus orientadores. Há que se rever os instrumentos gerenciais da Capes e considerar efetivamente a aplicação de parâmetros mais justos para avaliação dos cursos. Garantir o diálogo com a igualdade e a solidariedade pode ser garantia de vida para os nascituros e de um período de plena recuperação para as lactantes.

Em fichas de indicação de discentes para concorrerem aos processos seletivos de mestrado, por exemplo, há perguntas sobre as aparentes condições de saúde da candidata ou candidato. Pode não ser uma prática generalizada, mas denota o cuidado em se admitir bons candidatos, os quais, além da capacidade intelectual necessária para cumprir as demandas do curso, devem estar aparentemente aptos fisicamente. Entre essas condições fisiológicas, há que se subentender o estado fora da gestação.

Essa discussão deve ser iniciada ainda nos comitês de área. É no diálogo entre os comitês e a normativa vigente que pode ser ajustada a plataforma, apesar de não se tratar apenas de um problema de Tecnologia da Informação. Trata-se de uma proposta que visa garantir condições para a permanência de nossas pesquisadoras em programas de pós-graduação e corrigir as históricas distorções no acesso por questões de gênero. 


\section{CONSIDERAÇõES FINAIS}

Esse é o ponto em que encontramos nossas mulheres. Embora se dediquem acima de tudo a serem vistas como pesquisadoras competentes, capazes de produzir conhecimento, permanecemos no século XXI com os discursos pétreos da história da humanidade marcada por exclusão e preconceito. O presente trabalho suscita mais perguntas do que respostas, quando se trata de questionar mecanismos de avaliação que ignoram os direitos das mulheres, mesmo que estejam fora do mercado de trabalho. Nessa toada, ao analisar a aplicabilidade normativa da regulamentação prevista pela Capes, fundação vinculada ao Ministério da Educação no Brasil, buscou-se compreender até que ponto a efetividade dos comandos ali previstos atingem seus reais objetivos. Constatou-se, assim, que ainda que exista a garantia de licença-maternidade para as pesquisadoras bolsistas de pós-graduação, a maior parte delas desconhece a existência desta proteção. Notou-se, também, que se trata de uma interpretação extensiva do direito constitucional atribuído às mulheres empregadas no pós-parto para terem um período de dedicação integral aos filhos, nos casos de bolsistas de pós-graduação cujo vínculo com a universidade não é empregatício. Assim, verificou-se que, embora existam as portarias que garantem a licença -maternidade para as alunas de pós-graduação, no caso concreto, a efetividade dessa proteção para as bolsistas é matéria ainda pouco observada. $\mathrm{O}$ desconhecimento efetivo dos direitos e garantias da licença-maternidade nos programas de pós-graduação leva a crer que se trata de falta incentivo para as pesquisadoras no meio acadêmico. Nesse sentido, a possibilidade de reconhecimento das potencialidades e competências da mulher ultrapassa questões de gênero e pode repercutir na prospecção de jovens talentos. 


\section{REFERÊNCIAS}

ASSUNÇÃO, E. D. A extensão da licença-maternidade à adotante em face do princípio da igualdade. Disponível em: http: <//www.egov.ufsc. br/portal/sites/default/files/anexos/15850-15851-1-PB.pdf $>$. Acesso em: 23 maio 2017.

BRASIL. Constituição (1988). Constituição da República Federativa do Brasil. Brasília, DF: Senado Federal: Centro Gráfico, 1988.

CALIL, L. E. S. C. História do direito do trabalho da mulher: aspectos histórico-sociológicos do início da República ao final deste século. São Paulo: LTr, 2000.

DIAS, M. B. (Coord.). Diversidade sexual e direito homoafetivo. São Paulo. Editora Revista dos Tribunais, 2011. p. 535.

NEIVERTH, E.; M. H. B., MANDALOZZO, S. S. N. A Licençamaternidade e sua ampliação facultativa. Revista do Tribunal Regional do Trabalho da 9a Região, Curitiba, a. 34, n. 63, jul./dez. 2009.

NERY JUNIOR, N. Princípios do processo civil na Constituição Federal. 5. ed. (rev. e ampl.) São Paulo: Revista dos Tribunais, 1999, p. 42.

PROBST, E. R. A evolução da mulher no mercado de trabalho. Instituto Catarinense de Pós-Graduação (ICPG). Disponível em: <http:// www.posuniasselvi.com.br/artigos/rev02-05.pdf $>$. Acesso em: 30 maio 2017.

SANTOS, D. R. Da proteção à maternidade à licença compartilhada: um panorama histórico no Brasil e no direito comparado.

Monografia, Brasília, 2011. Disponível em: <http://bdm.unb.br/ bitstream/10483/1869/1/2011_DanielaRibeiroSantos.pdf >. Acesso em: 30 maio 2017.

SCHIFINO, B. S. V. O instituto da licença-maternidade e as alterações oriundas da lei n. 12.873/2013. Conteudo Jurídico, Brasilia-DF: 20 out. 2015. 
SILVA, A. M. O direito do trabalho da mulher e a maternidade. In: Âmbito Jurídico, Rio Grande, X, n. 40, abr 2007.

SOARES, S. IZAKI, R. S. A participação feminina no mercado de trabalho. Rio de Janeiro, 2002.

SOARES, S. IZAKI, R. S. Mães pós-graduandas conquistam o direito à licença-maternidade. Disponível em: <http://esjus.com.br/noticias/ maes-pos-graduandas-conquistam-direito-licenca-maternidade/ $>$. Acesso em: 10 abr. 2017. 